\title{
"Because of the baby": reduction on drug use during pregnancy
}

Eliza Maria Tamashiro 1

https://orcid.org/0000-0003-3983-3280

Helaine Maria Milanez 2

https://orcid.org/0000-0003-3211-9447

Renata Cruz Soares de Azevedo 3

https://orcid.org/0000-0002-7098-7109

\footnotetext{
1,3 Departamento de Psicologia Médica e Psiquiatria. Faculdade de Ciências Médicas. Universidade Estadual de Campinas. Rua Tessália Vieira de Camargo, 126. Cidade Universitária Zeferino Vaz. Campinas, SP, Brasil. CEP: 13.083-887. E-mail: elizatamashiro@yahoo.com.br

2 Departamento de Tocoginecologia. Faculdade de Ciências Médicas. Universidade Estadual de Campinas. Campinas, SP, Brasil.
}

\begin{abstract}
Objectives: evaluate changes in the use of psychoactive substances (PAS) throughout pregnancy.

Methods: longitudinal study, with pregnant women users of PAS at a prenatal follow-up.

Results: 76 pregnant women used: tobacco (84.2\%, $n=64)$, alcohol $(73.7 \%, n=56)$, cocaine $(27.6 \%, n=21)$, marijuana $(26.3 \%, n=20)$ and crack $(13.1 \%, n=10)$. Spontaneous interruption had occurred in $60 \%(n=6)$ of crack users, $57.1 \%(n=12)$ of cocaine and $50 \%$ $(n=28)$ of alcohol. After the Brief Intervention, 78.9\% (15 of the total of 19) of alcohol users and $70 \%$ (7 of the total of 10) of marijuana users discontinued the consumption and there was a reduction in smoking cigarettes.

Conclusions: the spontaneous reduction in the consumption of PAS and after the interventions, pregnancy is a window of opportunity to reduce the use of drugs.
\end{abstract}

Key words Pregnant women, Drug users, Drug abuse, Pregnancy, Brief Intervention

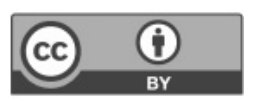




\section{Introduction}

National studies have pointed out an increase of alcohol consumption and other psychoactive substances (PAS) among women, particularly younger ones, 1,2 and also more difficulties in the cessation of smoking, when compared to men. Among the main aspects of the use of PAS by women, pregnancy is the impact, which can cause implications in maternal, fetal and newborn's (NB) health. 3,4

Alcoholic beverages use is associated with fetal growth restriction risk, and also congenital anomalies, miscarriage, fetal death (FD), prematurity and Fetal Alcohol Spectrum Disorder(FASD), which produces congenital changes and loss in cognitive and behavior development.3,4 Smoking during pregnancy increases the risks of miscarriage, ectopic pregnancy, premature rupture of membranes (PROM), fetal growth restriction and premature birth. 5 Pregnant women who use cocaine/crack can present a stronger risk of premature placental detachment, PROM and premature birth.3,4 Data on the impact of marijuana use during pregnancy are controversial, but heavy use appears to be related to preterm NB, low birth weight, and suspected longterm neurocognitive effects. 3,4

National and international studies point out to lower consumption rates during pregnancy,6,7 suggesting that pregnancy may be a period in which women are more motivated to decrease the use of PAS, being a suitable moment for Health professionals to intervene.

Among the ways to approach them, the Brief Intervention (BI) seeks in an empathic form, to calculate the risks and present them to the user, with an analysis based on the information about strategies in dealing with PAS consumption. It is a 5 to 45 minutes intervention, which emphasizes personal capacity and responsibility for the person's own behavior. ${ }^{8}$ BI studies on pregnant women who are also alcohol users noted higher abstinence rates, higher weight for the NB and a lower mortality rate, indicating that it can be an intervention which could be largely used with good results. ${ }^{9}$

The main purpose was to evaluate spontaneous or after intervention changes in the pattern use of PAS on pregnant women in prenatal follow up, being assisted at a high risk pregnancy university campus.

\section{Methods}

A longitudinal study. Training was performed on physicians and nurses from the prenatal outpatient clinic of the Centro de Atenção Integral à Saúde (CAISM) (Integral Health Care Center) at UNICAMP, asking them about the use of legal (tobacco cigarette and alcoholic beverages) and illegal PAS (marijuana, cocaine and crack) by pregnant women in the last three months. From positive answers, pregnant women were sent to a mental health professional that invited them to participate in the research and could confirm the use of several PAS by applying the ASSIST questionnaire (Alcohol, Smoking and Substance Involvement Screening Test) and another questionnaire, which asked the first consumption age, the type of PAS used before and after the pregnancy, if the consumption was interrupted and when it occurred, when did the patient began prenatal follow up at CAISM, how many consultations and interventions were made. Inclusion criterions were: pregnant women, age $\geq 18$, after the confirmation of the use of PAS by ASSIST, and who was willing to accept in participating in the research, signed an Informed Consent Form.

The pregnant women were evaluated on their first and last prenatal medical consultation. All participants received an information leaflet on the use of PAS and risks during pregnancy (Figure 1), along with 30-minute Brief Interventions (BI) discussing consumption-inducing factors and its consequences. When the pregnant women came to their obstetric consultations, during prenatal follow up, they went through shorter sessions (5-to-10minutes). The idea was to favor reflection about the usage and its consequences, and promote cessation/decrease strategies.

The data obtained were analyzed using the Statistical Analysis Systemprogram (The SAS System for Windows), with frequency statistical analysis for categorical and mean variables, standard deviation, minimum, maximum and median values for numeric variables. To compare PAS usage patterns, McNemar test was applied to categorized variables and Wilcoxon test for numeric variables. The significance level was $p<0,05$.

\section{Results}

Between 2013 and 2015, 76 women were included and 60 were followed up until childbirth (Figure 2). The most PAS used by pregnant women at the beginning of the research was tobacco $(84.2 \%, \mathrm{n}=64)$, followed by alcohol $(73.7 \%, \mathrm{n}=56)$, cocaine $(27.6 \%$, $\mathrm{n}=21)$, marijuana $(26.3 \%, \mathrm{n}=20)$ and crack $(13.1 \%$, $\mathrm{n}=10)$. The majority ofthe women $(72.4 \%, \mathrm{n}=55)$ reported the use of two or more PAS combined. Regards to the first experimentation age, it stands 


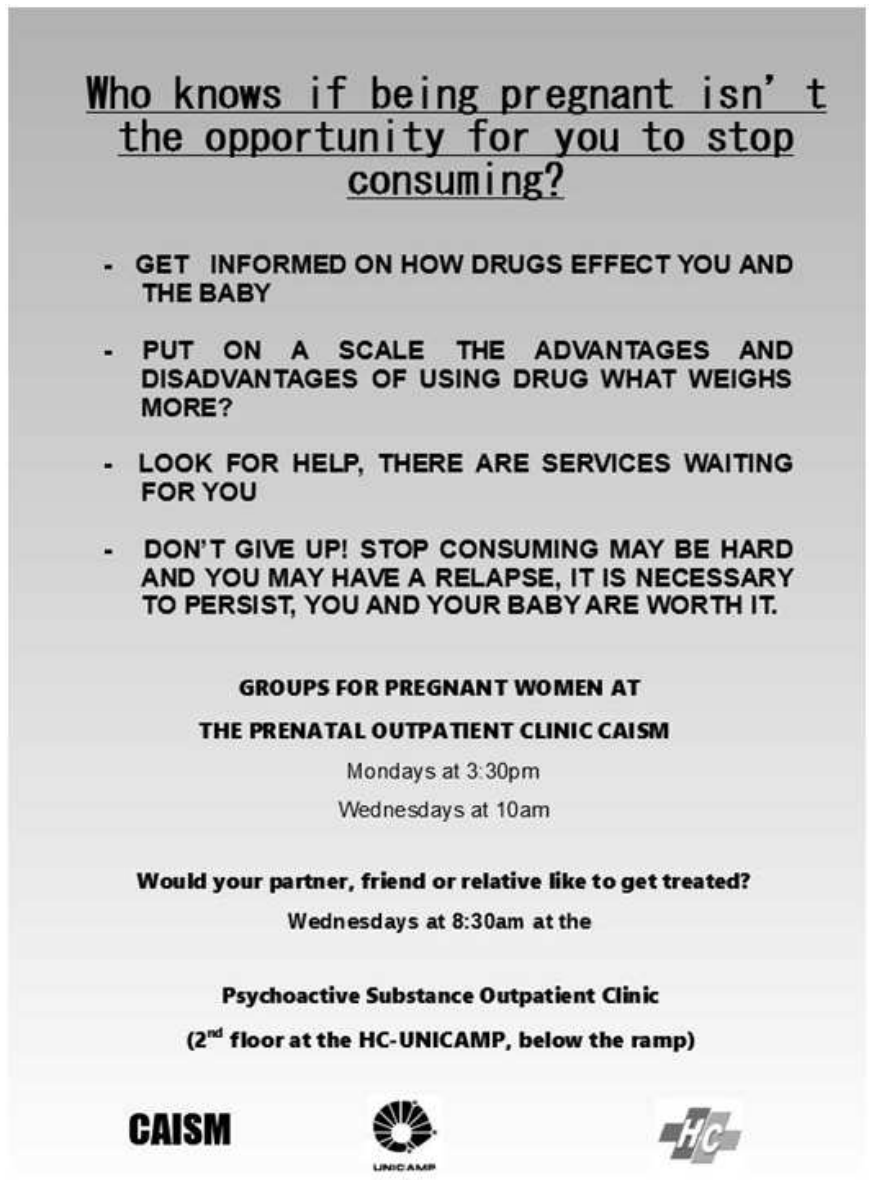

out that it is under the age of 18 for all the substances asked (tobacco $88.9 \%, \mathrm{n}=64$, alcohol $84.9 \%, \mathrm{n}=62$, marijuana $69.6 \%, n=32$, cocaine $59 \%, n=23$ and crack $50 \%, n=9$ ).

On average, women knew about their pregnancy at the $8^{\text {th }}$ week, they began the follow up at CAISMUNICAMP at approximately 18 weeks and had an average of 6.8 prenatal consultations. A large portion of illegal PAS users reported having spontaneously ceased usage before the first intervention of this research (marijuana 45\%, $\mathrm{n}=9$, cocaine $57.1 \%, \mathrm{n}=12$ and crack $60 \%, \mathrm{n}=10)$. As to the usage of legal substances, the majority of the smokers kept using tobacco cigarettes until the first intervention of this research $(87.5 \%, n=56)$ and although $50 \%(n=28)$ of alcohol users reported having interrupted the consumption during pregnancy, other $50 \%$ kept consuming until the beginning of BI.

All the pregnant women went through at least one BI (on average, they were submitted to 3.7 sessions, a minimum of 1 and the maximum of 15 , S.D. 2.7).

Sixty pregnant women were followed up until the end of their pregnancy. Of those women who did not cease spontaneously the consumption, most have stopped using drugs after the BI.

Although there was not an expressive smoking cessation rate, but there was a significant statistic reduction $(p=0.0102)$ on the number of cigarettes per week between the first interview (mean of 93.5) and the last interview at the end of the pregnancy (mean of 71.8 ), after the BI.

\section{Discussion}

The purpose of this study is to reinforce the fact that pregnancy is a window of opportunity to reduce the use of PAS. To value spontaneous cessation related to pregnancy, as pointed out by another study, ${ }^{6}$ and also brief motivational interventions that lead to a 


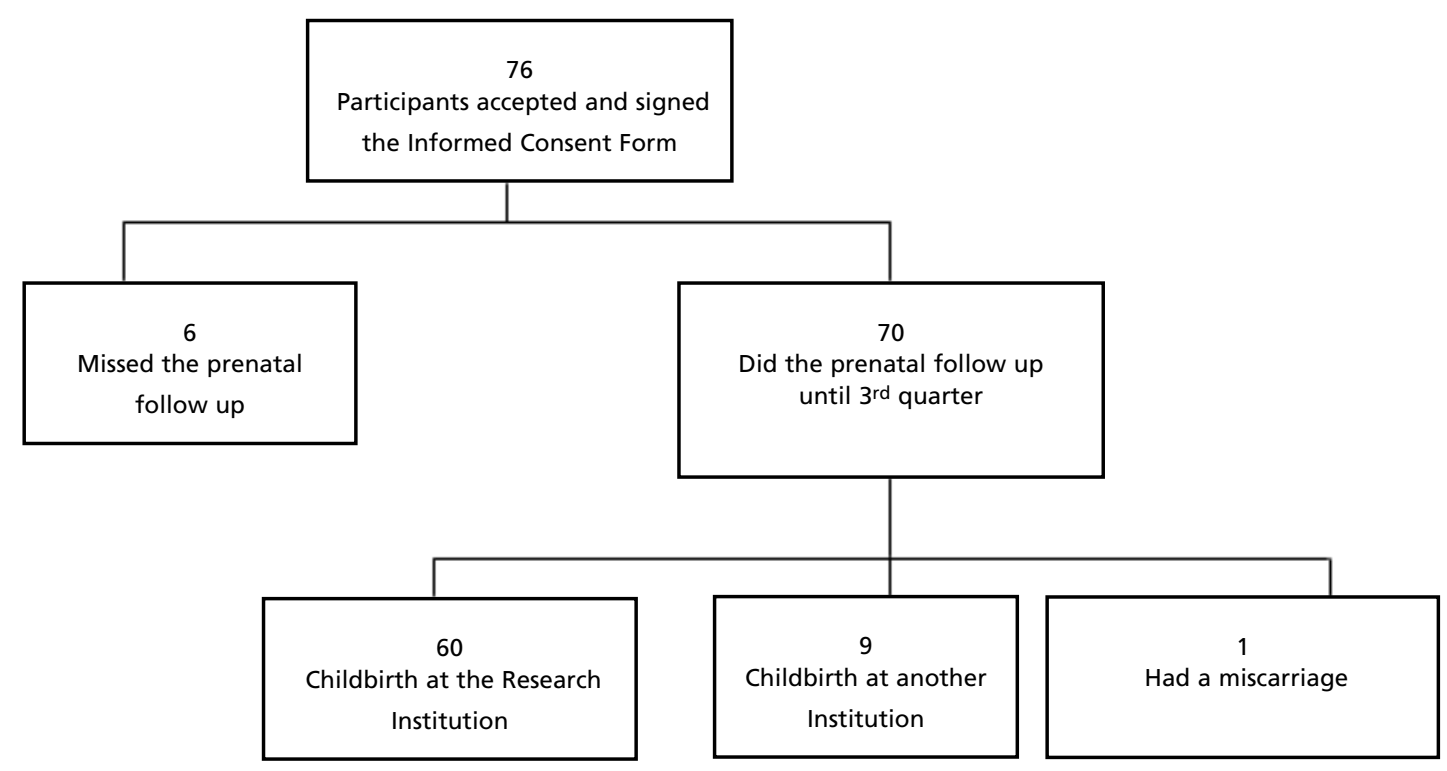

Table 1

Comparative variation* study on the usage pattern of psychoactive substances after the Brief Intervention.

\begin{tabular}{|c|c|c|c|c|c|}
\hline & \multicolumn{2}{|c|}{ Ceased using } & \multicolumn{2}{|c|}{ Continued using } & \multirow[t]{2}{*}{$p$} \\
\hline & $\mathrm{n}$ & $\%$ & $\mathrm{n}$ & $\%$ & \\
\hline Tobacco & 6 & 14.3 & 36 & 85.7 & 0.0937 \\
\hline Alcohol & 15 & 79.0 & 4 & 21.0 & 0.0011 \\
\hline Marijuana & 7 & 70.0 & 3 & 30.0 & 0.0293 \\
\hline Cocaine & 5 & 71.4 & 2 & 28.6 & 0.1718 \\
\hline
\end{tabular}

* McNemar Test.

stop in the consumption that should stimulate the inclusion of this issue in the prenatal follow up.

The starting age for PAS consumption among the evaluated women is in accordance with the latest national surveys 1,2 that indicate an increase and precocity in PAS experimentation of the female sex. This fact shows the necessity of widening prevention strategies that consider and include particularities related to sex and age.

The fact that most of the users (an exception made to smokers, and considering the absolute number of cocaine users, even with $p>0.05$ ) have ceased PAS consumption during pregnancy, strengthens the idea that pregnancy could be a motivating factor to decrease or interrupt drug use. In order to expand this behavior, the prenatal is a favo- rable time for women to go through interventions that inform about PAS usage and its possible consequences for the NB and their own health. It is also a suitable time to promote access to several treatment methods. To encourage detection and the right ways of approaching them by the Health professionals can improve and extend caring policies to this population during this period.

Significant cessation in alcohol and marijuana use, after BI in prenatal follow up, was compatible with the published data about brief intervention efficiency in pregnant women who are alcohol users. 9 Although smokers did not interrupt their smoking habits after discovering their pregnancy, they were willing to submit to motivational interventions and were able, if not to stop, to diminish the amount of 
cigarettes smoked until the end of the pregnancy, when compared to the number of cigarettes used at the beginning, this becoming a damage reduction strategy.

Despite positive results, one study limitation needs to be pointed out. The data obtained were based on the reports of women without supporting laboratorial tests. This may have caused underreporting of PAS use. However, the results showed greater proximity to real clinical conditions.

The acknowledgement of spontaneous PAS consumption cessation or even the reduction and receptivity to motivational interventions contribute in confirming gestational period as a window of opportunity to extend caring policies to this population, with potential positive impact on the develop-

\section{References}

1. Pinsky I, Laranjeira R, Caetano R. I Levantamento nacional sobre os padrões de consumo de álcool na população brasileira. Rev Bras Psiquiatr. 2010; 32 (3): 214-5.

2. Laranjeira R, Madrugada CS, Pinsky I, Caetano R, Ribeiro M, Mitsushiro SS. II Levantamento Nacional de Álcool e Drogas (LENAD) - 2012. São Paulo: Instituto Nacional de Ciências e Tecnologia para Políticas Públicas de Álcool e Outras Drogas (INPAD), UNIFESP- Universidade Federal de São Paulo; 2014.

3. Cook JL, Green CR, Ronde, Dell CA, Graves L, Ordean A, Ruiter J, Steeves M, Wong S. Epidemiology and Effects of Substance Use in Pregnancy. J Obstet Gynaecol Can. 2017; 39 (10): 906-15.

4. Forray A. Substance use during pregnancy [version 1; referees: 2 approved] F1000Research 2016, 5(F1000 Faculty Rev):887 (doi: 10.12688/f1000research.7645.1).

5. Wendell AD. Overview and Epidemiology of Substance Abuse in Pregnancy. Clin Obst Gyn. 2013; 56 (10): 91-6.

6. Reis LG, Silva CJ, Trindade A, Abrahão M, Silva VA Women who smoke and stop during pregnancy: who are they? Rev Bras Saúde Matern Infant. 2008; 8 (2): 217-21. ment of the pregnancy and of the childbirth, and on maternal and fetal health. Further studies are necessary to analyze the preservation of these changes on this period following childbirth, especially during lactation.

\section{Authors' contribution}

Tamashiro EM contributed in planning, data gathering and analysis, article writing and proofreading. Milanez HM contributed in the design, planning and article proofreading. Azevedo RCS contributed in the design, planning, data interpretation, article writing and proofreading. All the authors approved the final version of the article.

7. Chassevent-Pajot A, Guillou-Landréat M, Grall-Bronnec M, Wainstein L, Philippe H-J, Lombrail P, Vénisse J-L. Étude de prevalence des conduits addictives chez les femmes enceintes dans une maternité universitaire. La Revue Sage-Femme. 2011; 10: 221-9.

8. Silva CJ, Miguel AQC. Intervenção Breve. In: Diehl A...[et al]. Dependência Química: prevenção, tratamento e políticas públicas. Porto Alegre: Artmed; 2011. p. 242-51.

9. O Connor MJ, Whaley SE. Brief intervention for alcohol use by pregnant women. Am J Public Health. 2007; 97 (2): $252-8$.

10. Henrique IFS, Michele DD, Lacerda RB, Lacerda LA, Formigoni MLOS. Validação da Versão Brasileira do Teste de Triagem do Envolvimento com Álcool, Cigarro e outras Substâncias (ASSIST). Rev Assoc Med Bras. 2004; 50 (2): 199-206.

Received on August 27, 2018

Final version presented on June 12, 2019

Approved on August 2, 2019 